\title{
Respostas brasileiras à violência e novas mediações: o caso do Grupo Cultural AfroReggae e a experiência do projeto Juventude e Polícia
}

\author{
Brazilian responses to violence and new forms of mediation: \\ the case of the Grupo Cultural AfroReggae and the experience \\ of the project Youth and the Police
}

Sílvia Ramos ${ }^{1}$

\footnotetext{
${ }^{1}$ Centro de Estudos de Segurança e Cidadania da Universidade Candido Mendes. Rua da Assembléia 10, sala $810,20011-901$. Rio de Janeiro RJ. sramos@candidomendes. edu.br
}

\begin{abstract}
This article points out some aspects of the Brazilian's response to the urban violence, focusing both official policies of public security and civil society's actions. Identifies a lack on the national policy of public security, indicates successful governmental experiences carried out on some states and counties, and concentrates on the Police's actions. Analyzing the responses of the civil society, points out the experience of the Campaign for Disarmament and the role of the media. The paper shows the rising of groups of young people living in the favelas that became organized around cultural experiences that, in multiple aspects, characterize them as "new mediators" in the society. Those groups talk about violence and try to build new stereotypes that disassociate them from the criminal type. The article describes, in particular, the cases of the Grupo Cultural AfroReggae, from Rio de Janeiro, and the pilotexperience experienced with Minas Gerais State Military Police, called Project Youth and Police. The grupo AfroReggae is typically a "new mediator" and the initiative to carry out a work with the Police shows new perspectives in the traditional low profile participation of the civil organizations related to public security and projects of cooperation with the Police.
\end{abstract}

Key words Violence, Youth, Civil Society, Social Movements, Favelas
Resumo O artigo discute aspectos das respostas brasileiras à violência urbana, focalizando tanto políticas governamentais de segurança pública como ações da sociedade civil. Identifica e inexistência de uma política nacional de segurança pública, indica experiências governamentais bem-sucedidas em estados e municípios e focaliza a atuação das polícias. Ao analisar as respostas da sociedade civil, destaca a experiência da campanha do desarmamento e o papel da mídia. O trabalho situa o surgimento de grupos de jovens de favelas organizados em torno de experiências culturais que, em vários aspectos, se caracterizam como "novos mediadores" na sociedade. Esses grupos tematizam a violência e procuram construir novos estereótipos que dissociem os jovens de periferia das imagens de criminalidade. $O$ artigo descreve em particular o caso do grupo cultural AfroReggae, do Rio de Janeiro, e a experiência piloto em batalhões da Polícia Militar de Minas Gerais, o projeto Juventude e Polícia. Argumentase que o grupo AfroReggae é tipicamente um novo mediador e que a iniciativa de realizar um projeto com a polícia abre novas perspectivas no campo da reduzida tradição participativa de organizações da sociedade civil na esfera da segurança pública e em projetos de cooperação com a polícia.

Palavras-chave Violência, Juventude, Sociedade civil, Movimentos sociais, Favelas 


\section{Introdução}

O Brasil tem uma das mais altas taxas de homicídio do mundo. No centro do problema estão os jovens - especialmente os jovens pobres e negros moradores de favelas e periferias urbanas -, seja como vítimas, seja como autores de violência. As respostas que tanto o Estado como a sociedade civil brasileira têm dado ao problema da criminalidade e da violência são lentas e insatisfatórias. No entanto, na década de 1990, surgiram, em diferentes cidades, iniciativas artísticas e culturais lideradas por jovens de favelas e das periferias dos centros urbanos. Ainda que heterogêneas e não articuladas entre si, essas experiências vêm se configurando como importantes esforços de criação de culturas de paz diante das dinâmicas de conflitos urbanos.

O objetivo deste artigo é discutir aspectos das respostas brasileiras à violência urbana, focalizando tanto políticas governamentais de segurança pública como ações da sociedade civil. Entre diferentes respostas, identificarei o surgimento de grupos que, em vários aspectos, se caracterizam como "novos mediadores" na sociedade. Em particular, descreverei o caso do grupo cultural AfroReggae, do Rio de Janeiro, e a experiência piloto desenvolvida em parceria com o Centro de Estudos de Segurança e Cidadania (Cesec) em batalhões da Polícia Militar de Minas Gerais, o projeto Juventude e Polícia. Vou argumentar que o grupo AfroReggae é tipicamente um novo mediador e que a iniciativa de realizar um projeto com a polícia não só é radicalmente nova, como abre novas perspectivas no campo da reduzida tradição participativa de organizações da sociedade civil na esfera da segurança pública e em projetos de cooperação com a polícia.

\section{O sistema de justiça criminal, as políticas de segurança e a polícia}

As taxas de mortes por causas externas nos principais centros urbanos brasileiros estão entre as mais altas do continente, expressando uma tendência verificada desde a década de 1980, acentuando-se nos anos 901. Desde 2003, o Brasil ultrapassou o número de 50 mil pessoas assassinadas por ano. As vítimas da violência letal intencional são majoritariamente jovens, do sexo masculino, negros e moradores das favelas e bairros pobres dos centros urbanos ${ }^{2}$.

Com que políticas públicas de segurança o País tem respondido ao fenômeno da crescente vio- lência urbana? Nos mais de 20 anos desde que o processo de transição da ditadura militar teve início (1985), o setor que menos progressos fez em relação à modernização e à democratização foi o de Justiça Criminal, em particular, o das instituições policiais ${ }^{3}$. Apenas na segunda metade da década de 1990 começaram a ser registrados os primeiros esforços sistemáticos de elaboração de políticas públicas de segurança baseados numa perspectiva contemporânea, identificada com a combinação entre eficiência e direitos humanos. Até então, o tema era relegado, pela maioria dos governos, às esferas corporativas das próprias polícias $^{4,5}$. O silêncio em relação à escalada de violência letal predominou também entre amplos setores intelectuais, na mídia e mesmo entre as organizações não-governamentais durante os anos 80 e em parte da década de 1990. Efetivamente, nos contextos acadêmico e universitário, salvo raras exceções, são relativamente recentes a criação de centros de pesquisa voltados para os temas da violência com foco em segurança pública.

O perfil socioeconômico das principais vítimas da violência letal e sua baixa capacidade de pressão política podem ajudar a explicar o despertar tardio dos governos, da mídia e da sociedade civil brasileira para o tema da segurança pública e para a necessidade de investir em modernização, controle e democratização das instituições de polícia. A maioria das polícias civis e militares nos Estados da Federação foram se degradando e algumas se tornaram violentas e ineficientes. O crime organizado que se estrutura em torno do tráfico de armas e drogas, por meio de mecanismos em níveis diversos, corrompeu amplos segmentos das corporações policiais, em alguns casos atingindo desde as bases até as chefias ${ }^{6}$. Em alguns Estados, a violência policial transformou-se em um problema que afeta as corporações e vitima as populações pobres, que se vêem encurraladas entre a violência dos grupos armados de traficantes e a violência e a corrupção policiais.

No Estado do Rio de Janeiro, segundo os dados da Secretaria de Segurança Pública para o ano de 2005 , a polícia é responsável por $14,2 \%$ das mortes violentas intencionais. Os "autos de resistência" - isto é, as mortes registradas como decorrentes de confrontos com a polícia, - aumentaram $280 \%$ em seis anos (de 289, em 1999, subiram para 1.098, em 2005), denotando um crescimento extraordinário do uso da força letal pela polícia. A violência policial também assume, tal como as taxas de homicídios na cidade, uma geografia específica, estando fortemente concentrada na Zona Oeste e nos subúrbios, as áreas mais pobres da cidade. Em 2003, 
quatro entre os batalhões que patrulham os subúrbios do Rio $-3^{\circ} \mathrm{BPM}$ (Méier), $9^{\circ}$ (Rocha Miranda), $16^{\circ}$ (Olaria) e $22^{\circ}$ (Benfica) - mataram 501 civis, enquanto quatro dos batalhões instalados na Zona Sul-2 ${ }^{\circ}$ BPM (Botafogo), $19^{\circ}$ (Copacabana), 23(Leblon) e $31^{\circ}$ (Recreio dos Bandeirantes) - mataram 202. A baixa presença de organizações de direitos civis nessas áreas, aliada a uma espécie de "naturalização" da idéia de que conflitos em favelas provoquem vítimas civis, pode ajudar a compreender por que esses números são tão altos em algumas regiões.

O fenômeno do uso excessivo de força letal pela polícia é um problema grave em vários Estados da federação. Muitas polícias estaduais nem mesmo divulgam estatísticas sobre mortes ocorridas em ação. Em São Paulo e em Minas Gerais, onde há dados, vêm sendo colocadas em prática políticas de redução da violência policial letal. Em São Paulo, as mortes em confronto com policiais caíram significativamente: de 573, em 2004, para 300, em 2005 (www.ssp.sp.gov.br). Em Minas, elas tiveram uma pequena redução: de 103, em 2004, para 99, em 2005 (dados do Comando de Policiamento da Capital).

As características das mortes em confronto são indicadoras das suas dinâmicas. Um estudo minucioso dos autos de resistência, focalizando os anos de 1993 a 19967, na cidade do Rio de Janeiro, revelou que as vítimas são majoritariamente jovens do sexo masculino (de 15 a 29 anos, com ênfase na faixa de 20 a 24) e que $64 \%$ são negros (pretos e pardos), contrastando com a presença de 39\% de negros na população carioca. $\mathrm{O}$ estudo também mostrou que as mortes decorrentes das ações policiais concentram-se em favelas e que quase a metade dos corpos recebeu quatro disparos ou mais e $65 \%$ dos cadáveres apresentavam pelo menos um tiro nas costas ou na cabeça, configurando casos de execuções sumárias. O fato é que, no Rio de Janeiro, a violência policial encontra-se fora de controle dos comandos superiores. $\mathrm{Na}$ medida em que a "licença para matar" foi concedida aos policiais que atuam nas favelas e bairros pobres, abriu-se um amplo terreno para o crescimento da corrupção e para os chamados "acertos" ou "arregos" entre traficantes e agentes policiais ${ }^{8}$.

Em relação às políticas de segurança no Brasil, algumas experiências importantes se destacam. Recentemente, alguns municípios passaram a incorporar pesquisadores e organizações da sociedade civil na elaboração e execução de políticas públi$\mathrm{cas}^{9}$. O caso de Diadema (SP), que reduziu as taxas de homicídio, roubo e furto a partir de uma política integrada de ação policial, controle de bares e programas dirigidos a jovens, é o mais emblemáti- co, por ter tornado uma área estigmatizada da região metropolitana de São Paulo em um casomodelo que vem sendo copiado por muitos municípios do País ${ }^{10}$.

No âmbito dos governos estaduais, ainda que as ações de redução da violência sejam fortemente concentradas nos esforços de repressão, algumas iniciativas de modernização das polícias têm acontecido. O caso mais bem-sucedido é o de Minas Gerais: há alguns anos, a Polícia Militar mantém convênio com o Centro de Estudos de Criminalidade e Segurança Pública (Crisp) para monitoramento da criminalidade. Em 2005, a Secretaria de Defesa Social criou o Instituto de Gestão em Segurança Pública (Igesp), que integra as polícias com órgãos do sistema de justiça criminal (Ministério Público, Varas da Infância, Sistema Penitenciário etc.). Em reuniões mensais, comandantes responsáveis pelas áreas prestam contas de metas estabelecidas e definem novos objetivos a serem cumpridos, nos moldes do CompStat, de Nova York (www.nypd.gov).

Em âmbito nacional, em 2002, durante o processo das eleições presidenciais, o Partido dos Trabalhadores apoiou a elaboração de um Programa Nacional de Segurança que contou com amplo processo de consultas e a participação de especialistas de vários Estados. Pela primeira vez, o País contou com um programa que propunha combinar políticas sociais e preventivas com políticas policiais e repressivas e controle e modernização das polícias.

Passados mais de três anos do início da gestão Lula da Silva, contudo, uma parte ínfima das propostas foi cumprida e o Programa Nacional de Segurança foi virtualmente abandonado. A Secretaria Nacional de Segurança Pública (Senasp), criada na gestão Fernando Henrique, operou recursos ainda menores que os do governo anterior. O Fundo $\mathrm{Na}$ cional de Segurança Pública, para investimentos em todo o País, contou, em 2005, com aproximadamente R\$170 milhões. O orçamento da segurança pública, apenas no Estado de São Paulo, correspondeu a R $\$ 6$ bilhões.

Se planejamentos e ações integradas de segurança pública em nível nacional ocorrerão ou não, em grande medida, isto dependerá da capacidade de pressão que a sociedade for capaz de exercer para que os governos, nos três âmbitos, reconheçam a urgência dos temas da violência e da segurança pública. Com raras exceções, as respostas governamentais ao fenômeno da violência - independentemente de orientação partidária - parecem ser, ainda nesses primeiros anos do novo século, a lentidão e a baixa qualificação. Em larga medida, 
prevalece a naturalização da violência, favorecida pela quase incapacidade de vocalização de suas principais vítimas, as populações marginalizadas. A despeito de experiências importantes em alguns Estados, predominam como padrão, em todo o Brasil, instituições policiais que não fizeram a transição da proteção do Estado, como era seu papel na ditadura militar, à proteção dos cidadãos, especialmente os cidadãos pobres, que muitas vezes são tratados como inimigos ${ }^{3}$. Em termos nacionais, inexiste qualquer diretriz que possa ser chamada de política nacional de segurança pública.

\section{O Estatuto do Desarmamento e o papel da mídia}

Entre as respostas da sociedade civil, em 2003, um importante passo foi dado para reduzir as mortes por armas de fogo. Sob a liderança de organizações não-governamentais que mobilizaram grandes manifestações públicas, a articulação com parlamentares comprometidos com políticas de paz, e o apoio de parte importante da mídia, foi aprovado, no Congresso Nacional, o Estatuto do Desarmamento, que prevê dispositivos para controlar a venda e a posse de armas de fogo e proibir o porte. Milhares de armas foram recolhidas (segundo o Instituto Sou da Paz, 430 mil armas de fogo foram entregues até final de 2005), numa inédita campanha nacional em favor da paz. Em outubro de 2005, um plebiscito nacional perguntou se a população concordava com a proibição da venda de armas de fogo em território nacional e a maioria disse "não". A despeito do resultado negativo dessa etapa da implementação do Estatuto, o fato de uma "política de segurança" ter se iniciado em organizações da sociedade civil, ter recebido a atenção dos meios de comunicação, ter saído vitoriosa em votação no Congresso e se tornado política de Estado pode ser considerado um caso paradigmático na área de controle da violência no Brasil.

É digno de nota o importante papel que os meios de comunicação têm desempenhado no agendamento de políticas públicas de segurança e no controle externo das polícias ${ }^{11}$. A despeito dos problemas que ainda persistem na cobertura sobre criminalidade e a violência, os principais jornais do país fizeram profundas mudanças nos últimos anos, alterando significativamente o estereótipo do "repórter policial". Nos grandes jornais, os repórteres que cobrem a área de criminalidade e segurança pública não são exclusivos da área de "polícia" e buscam crescentemente ouvir fontes não-policiais nas matérias investigativas.
Jovens das favelas e das periferias: novos mediadores

No contexto das respostas civis à violência, podese vislumbrar um importante e recente processo de mobilização de jovens de favelas e bairros de periferia. São projetos ou programas locais baseados em ações culturais e artísticas, freqüentemente desenvolvidos e coordenados pelos próprios jovens. Exemplos dessas iniciativas são os grupos Olodum e Timbalada, em Salvador; o AfroReggae, o Nós do Morro, a Cia. Étnica de Dança e a Central Única de Favelas (Cufa), no Rio de Janeiro, além de centenas de agrupamentos mobilizados em torno da cultura hip hop nas periferias de São Paulo, Porto Alegre, Belo Horizonte, Recife, Brasília e São Luís.

Esses grupos expressam, por meio de diferentes linguagens, como a música, o teatro, a dança e o cinema, idéias e perspectivas dos jovens das favelas. Ao mesmo tempo, buscam produzir imagens alternativas aos estereótipos da criminalidade associados a esse segmento da sociedade e "disputam" os jovens dessas áreas com o tráfico de drogas, exercendo uma sedução ligada ao glamour da arte, à visibilidade e ao sucesso.

Em geral, esses grupos e projetos caracterizamse por quatro aspectos inovadores no repertório de princípios das entidades de direitos humanos, das Organizações Não-Governamentais (ONGs) e do campo da esquerda, na qual as iniciativas da sociedade civil brasileira tradicionalmente se inscrevem:

1) Estão interessados no mercado e, ao contrário das ONGs tradicionais, buscam alternativas de renda e emprego para seus integrantes, além de colocação no mercado e profissionalização. Nesse sentido, criam uma cultura oposta à do "sem fins lucrativos", que caracteriza as ONGs brasileiras ${ }^{12}$. Alguns grupos operam com duas identidades jurídicas simultâneas: uma como "ONG" (a partir da qual recebem doações de fundações internacionais e nacionais) e outra como "empresa cultural" (para contratos de shows, discos ou filmes). Embora reafirmem o pertencimento ao campo do "trabalho social", alguns grupos procuram depender cada vez menos das doações internacionais, buscando sustentação como empresas culturais que disputam o mercado.

2) Têm um forte componente de investimento nas trajetórias individuais e nas histórias de vida. Valorizam o campo simbólico da subjetividade e investem na formação de artistas e líderes cuja fama passa a servir como modelo. Numa contraoperação de criação de estereótipos, procuram 
construir imagens fortes de jovens favelados que, contrariando a profecia, tornaram-se cineastas, artistas de teatro ou músicos. Em outras palavras, nesses grupos, as estratégias de mídia, o sucesso e a fama são entendidos como ingredientes políticos de militância. Usam insistentemente a grande mídia e buscam parcerias com os grandes conglomerados de comunicação, aparecendo não só como artistas, mas como lideranças que falam em nome dos jovens das favelas. Nesse sentido, eles se afastam do modelo sindical e associativo de esquerda, no qual a cultura do "coletivo" impera sobre os desvios individualistas.

3) Têm um forte componente de afirmação territorial, sendo freqüente que os nomes dos grupos, as letras das músicas, as camisetas e as roupas reafirmem permanentemente os nomes das comunidades de origem (Vigário Geral, Vidigal, Cidade de Deus, Pelourinho, Candeal, Alto Vera Cruz, Alto do Pina etc.). Curiosamente, a intensa e reiterada afirmação de compromisso territorial não se traduz em bairrismo ou nacionalismo. Combinam o "amor à comunidade" com a adesão aberta a signos da globalização (Coca-Cola, Nike etc.) e produzem conexões entre o local e o universal via internet, sites e revistas. Atribuem alta prioridade aos intercâmbios com outras comunidades (inclusive com jovens de classe média), às viagens nacionais e internacionais.

4) Assumem um forte componente de denúncia do racismo e de afirmação racial negra, seja nas letras das músicas, nas indumentárias ou nos nomes (AfroReggae, Companhia Étnica, Negros da Unidade Consciente, Mano Brown, Zé Brown etc.). Sem necessariamente pertencerem ao chamado "movimento negro", esses jovens referem, em músicas ou entrevistas, permanentemente o fato de serem "negros" e "favelados". A negritude e o pertencimento à periferia encontram uma fórmula curiosa que combina denúncia com orgulho (racial e territorial), muitas vezes cantada e dançada numa explosão de alegria, como ocorre com o Olodum, a Timbalada e o AfroReggae. Isso os situa em uma posição oposta à do silêncio sobre a problemática da desigualdade racial (que predomina nas expressões culturais tradicionais como o samba e nas expressões culturais jovens) e ao mesmo tempo numa posição diferente da tradicional denúncia do racismo usada pelo movimento negro, baseada na idéia de vitimização. As expressões "auto-estima" e "atitude" são as que melhor definem, em linguagem nativa, a idéia de que se pretende forjar novas imagens associadas aos jovens negros das favelas.

Juntamente com o fenômeno de criação das
"ONGs locais", identificado por analistas das favelas ${ }^{13}$, esses projetos e iniciativas - heterogêneos e não articulados entre si, mas que crescem consistentemente em várias cidades - vêm se tornando importantes, não só como pólos de construção de uma cultura alternativa ao tráfico, mas como mediadores, ou seja, como tradutores entre a juventude das favelas, de um lado, e governos, mídia, universidades e, muitas vezes, atores internacionais, como fundações e agências de cooperação, de outro. Estabelecem pontes entre os mundos fraturados representados pela cidade formal e pela favela. Freqüentemente são os únicos pontos de contato para quem pretende entender o que se passa com os jovens moradores de bairros pobres das cidades.

No que diz respeito à violência e à criminalidade, a maioria dessas iniciativas se equilibra entre a denúncia da violência policial, de um lado, e a busca de autonomia em relação ao despotismo dos grupos armados de traficantes, de outro. Alguns desses grupos procuram exercer papéis de mediadores na "guerra" entre facções do tráfico de drogas e assumem abertamente a missão de "tirar jovens do tráfico"8,14,15, mas esta não é necessariamente uma regra comum a todos. Por exemplo, o grupo Nós do Morro, do Rio de Janeiro, recusa a discussão sobre o tráfico de drogas e não refere qualquer compromisso associado à criação de alternativas à criminalidade entre seus objetivos (www.nosdomorro.com.br). Outras iniciativas, por sua vez, assumem posições até mesmo ambíguas em relação ao "mundo do crime". É o caso de grupos de hip hop que se identificam com os "manos" presos e se concentram na denúncia de que a criminalidade é associada, como estereótipo, aos jovens negros das periferias.

Essas iniciativas - aqui identificadas como novas mediações nas respostas à violência - não são, fique claro, as únicas, nem necessariamente as mais eficientes para "tirar jovens do tráfico". Um número incontável de grupos religiosos, especialmente de orientação pentecostal, encontra-se, hoje, dedicado à conversão religiosa de jovens que ingressaram no crime. Além disso, em favelas e bairros pobres proliferam escolinhas de futebol $\mathrm{e}$ programas esportivos voltados para combater o ócio, descobrir talentos e criar alternativas profissionais. Mesmo no campo da cultura, desenvolvemse numerosos projetos de dança, circo, música e teatro, tanto governamentais como privados, voltados para o lazer e a profissionalização de adolescentes. As marcas específicas dos novos mediadores são: a liderança dos grupos pelos próprios jovens oriundos das favelas e a produção de um discur- 
so na primeira pessoa; a capacidade de expressar signos com os quais os jovens das favelas se identificam e ao mesmo tempo criar modelos que recusem as imagens tradicionais dos jovens das favelas; a criação de novas metáforas por força das histórias de vida; a capacidade de transitar na grande mídia e na comunidade, entre diferentes classes socais, facções e governos, isto é, transitar entre o local e o universal.

Por último, os jovens mediadores não podem ser tomados como exemplos de espíritos contemporâneos sintonizados com os valores da modernidade. Formam grupos heterogêneos, mas predominantemente masculinos. Evidentes traços de misoginia ou de homofobia podem ser observados nas práticas e nas construções discursivas de vários desses grupos, assim como na "cultura" hip hop ${ }^{8,16}$.

\section{O grupo cultural AfroReggae}

O grupo cultural AfroReggae é uma organização não-governamental, criada em 1993, com base na favela de Vigário Geral, na cidade do Rio de Janeiro. O grupo foi criado no mesmo ano em que ocorreu a chacina de Vigário Geral, quando 21 moradores inocentes foram mortos por policiais, numa operação ilegal, resultante de um "acerto" malsucedido entre policiais e traficantes. O objetivo do grupo é oferecer formação cultural e artística para jovens moradores de favelas de modo que eles tenham meios de construir suas cidadanias e, assim, possam escapar do caminho do narcotráfico e do subemprego, transformando-se também em multiplicadores para outros jovens. As principais atividades desenvolvidas pela organização são oficinas de percussão, teatro, circo, capoeira, vídeo e informática nas favelas de Vigário Geral, Parada de Lucas, Cantagalo, Ramos e Complexo do Alemão. O grupo criou, ao longo de sua existência, uma banda profissional (banda AfroReggae) e oito outros grupos que se apresentam em espetáculos (www.afroreggae.org.br). A banda AfroReggae se apresenta em grandes concertos no Brasil e faz freqüentes apresentações internacionais. Por isso, adquiriu visibilidade na mídia e aparece com freqüência na televisão. A entidade desenvolveu uma larga experiência de trabalho com jovens e crianças de baixa renda, mas possui uma linguagem que atinge jovens de diversas classes sociais. Paralelamente à organização não-governamental, o AfroReggae criou uma empresa que gera recursos com shows e apresentações e emprega jovens nas diversas carreiras de produções artísticas.
Essa produtora, juntamente com doações internacionais (Ford Foundation, Kellog Foundation, HP Foundation, Avina e outras), convênios nacionais (prefeituras, ministérios e governos estaduais) e patrocinadores (TV Globo, Petrobras e outros), financia as ações da organização não-governamental. O AfroReggae é tipicamente um novo mediador. Procura aproximar a favela da classe média numa via de mão dupla. Com o projeto Conexões Urbanas (concertos musicais em favelas com artistas e grupos de sucesso), o AfroReggae leva músicos e bandas famosas para as favelas e, por outro lado, "apresenta" a favela para artistas e convidados dos shows (gestores públicos, profissionais de mídia, líderes empresariais, intelectuais, visitantes estrangeiros etc.). Utiliza, assim, as dimensões do mercado e do comunitário, concentra seus esforços na afirmação territorial e racial da favela e produz um discurso na primeira pessoa em nome dos jovens das periferias.

Há inúmeros riscos em um percurso como este. Entre eles, o de cooptação dos projetos pelo Estado, ou pelas empresas que os patrocinam, o de instrumentalização da "cultura a serviço do social" e o da criação de novos estereótipos, ao mostrar garotos negros, bem-comportados, que teriam "escapado do crime" e se apresentam tocando instrumentos de percussão ${ }^{17,18}$. Uma das indicações de que o grupo parece reconhecer alguns desses riscos é sua recusa em multiplicar seus núcleos para trabalhar em escala. Considera que não deve substituir o Estado na geração de alternativas para jovens das classes populares e declara que opera no campo simbólico, mostrando a potencialidade dessas ações por meio da criação e divulgação de modelos e pilotos ${ }^{16}$. No plano musical, o grupo foge do estilo bem-comportado e procura uma solução estética própria. O antropólogo Hermano Vianna (CD Nova Cara) definiu assim a música da banda AfroReggae: o multi-estilo afroreggae é produto do encontro de algumas das manifestações mais vitais surgidas na música brasileira em tempos recentes: mangue beat; rap paulistano; samba-reggae baiano; funk carioca. Aqui $e$ ali os ecos do reaggae jamaicano traduzido pelo Rappa, do hip-hop-hardcore transformado pelo Planet Hemp, das batidas de xaxado e techno ou de toques de capoeira e candomblé.

Em relação às facções de traficantes que dominam as favelas do Rio de Janeiro, o grupo busca uma posição de independência, o que tem permitido a apresentação de shows em comunidades dominadas por diferentes comandos, apesar de ter origem em uma favela ocupada por uma facção que está em guerra há mais de 25 anos com a facção da 


\section{O projeto Juventude e Polícia}

Em 2002, a banda AfroReggae produziu um videoclipe para a música Tô bolado (música que conta a história da chacina de Vigário Geral), em que sucessivas imagens de violência policial se sucediam, configurando uma franca oposição do AfroReggae à polícia. No mesmo ano, um dos membros fundadores do grupo foi alvejado por um tiro de fuzil, numa operação policial comandada pelo Batalhão de Operações Especiais da PM do Rio de Janeiro (Bope) dentro de Vigário Geral. Quase todos os jovens ligados ao AfroReggae tinham experimentado situações de violência, corrupção e humilhação por parte de policiais, compondo um vasto repertório de ódios e ressentimentos que constituía uma caudalosa cultura "antipolícia" no grupo. No final de 2002, surpreendentemente, a coordenação da entidade procurou o Centro de Estudos de Segurança e Cidadania (Cesec), da Universidade Candido Mendes, e disse que gostaria de elaborar um projeto com a polícia (e não contra a polícia, como seria de se esperar). Um projeto de invasões culturais nos batalhões foi apresentado à Fundação Ford, que o aprovou imediatamente. As negociações com a Polícia Militar do Rio de Janeiro se frustraram após meses de tentativas e não foi possível desenvolver a proposta naquele Estado. Em 2004, a Secretaria de Defesa Social e a Polícia Militar de Minas Gerais convidaram o AfroReggae e o Cesec para levarem o projeto aos batalhões de Belo Horizonte.

O projeto desenvolveu-se, inicialmente, como um piloto de quatro etapas, voltado para estabelecer um diálogo entre a cultura dos jovens e a cultura policial, reduzindo a distância entre esses dois grupos por meio da música e da arte. Foram realizados workshops de percussão, teatro, grafite, dança e shows dentro de dois batalhões de Belo Horizonte. Participaram dessas atividades cerca de 70 policiais de cada unidade (cada batalhão conta com um efetivo de aproximadamente 800 policiais). Os instrutores dos workshops foram jovens do AfroReggae, incluindo o artista baleado pela polícia em 2002, e o percussionista da banda, que

tivera um tímpano perfurado em uma abordagem policial. Os resultados surpreendentes das quatro semanas iniciais (uma semana em cada mês) estabeleceram a importância de um instrumento original de integração da polícia com os jovens. Ao longo dessa primeira etapa, o impacto das ações dentro dos quartéis e nos meios de comunicação indicou que é possível valorizar os aspectos humano, lúdico e artístico de policiais - como esses grupos têm feito com os jovens -, ao mesmo tempo em que reduzem os preconceitos dos policiais sobre os moradores das favelas e periferias.

Em 2005, a PM de Minas Gerais avaliou que o resultado das ações do primeiro ano foram tão positivas que resolveu dar continuidade à parceria e convidou o AfroReggae e o Cesec para capacitarem policiais que passaram a trabalhar permanentemente - através de oficinas de percussão, grafite, dança, basquete e teatro - com jovens de favelas de Belo Horizonte. Produziu-se o documentário Polícia Mineira, que foi dirigido por um profissional do mercado, o diretor Estevão Ciavatta. Em 2006, o governo de Minas estabeleceu com o AfroReggae e o Cesec um convênio para dar continuidade ao projeto.

Em janeiro de 2006, após a exibição do documentário no QG da Polícia Militar do Rio de Janeiro, o secretário de segurança daquele Estado, reconhecendo os efeitos positivos da proposta realizada em Belo Horizonte, solicitou sua implantação nos batalhões do Rio. Um diálogo inicial foi estabelecido e negociações estão em andamento para verificar a viabilidade e o formato que melhor se adéqua à realidade local.

Entre os aspectos significativos da experiência, se comparada às formas tradicionais de trabalho de sensibilização das polícias (cursos, reuniões e palestras de direitos humanos), vale a pena enfatizar os seguintes elementos-chave:

1) A experiência mobiliza não apenas a razão, mas corações, mentes e especialmente corpos, através de oficinas de música, teatro, grafite e outros. É preciso considerar que a posição tradicionalmente "defensiva" da cultura corporativa dificulta a maioria das tentativas de ensino de direitos humanos a partir de argumentação crítica.

2) A essência da intervenção não é apenas "mudar o policial", ensinando-lhe, intelectualmente, algo que, aparentemente ele não quer aprender, ou resiste a incorporar, mas propor experiências novas e inusitadas tanto para eles como para os jovens que pela primeira vez entram num batalhão de polícia. São jovens instrutores que têm a "atitude" do jovem da favela vivendo uma experiência que mobiliza seus estereótipos em relação à polícia, $\mathrm{e}$ 
provoca no policial os sentidos do ritmo e da plasticidade. O essencial está na troca, e ela se realiza diretamente entre policiais e jovens, sem mediadores (professores de direitos humanos). Os policiais e os jovens, que foram construídos como grupos antagônicos, descobrem rapidamente que partilham mais identidades do que supunham. Não só a origem freqüentemente comum vem à tona, com o estabelecimento de proximidades culturais, mas a vivência da discriminação como grupos estigmatizados na sociedade (como "jovens favelados", por um lado, e como "polícia", por outro). Os dois grupos, tendo estabelecido laços, se surpreendem mutuamente e se percebem protagonistas de um novo momento diante do olhar da sociedade.

3) Som e imagem são centrais. A idéia é questionar a imagem que a sociedade e a juventude têm da polícia e a imagem que a polícia e a sociedade têm dos jovens negros das favelas. A polícia "é imagem": a farda, a arma, a estética militar, a viatura caracterizada. Por sua vez, o AfroReggae "é imagem": os artistas, os shows, a imagem da favela e dos jovens. Todas as etapas do projeto foram filmadas, fotografadas e registradas em áudio. Duas experiências revelaram-se importantes: as oficinas de vídeo e as sessões de fotos. Nesses encontros os policiais se viam tal como foram vistos pela lente do fotógrafo e discutiam os "efeitos" que as imagens produziriam "nos outros" (outros policiais e na sociedade). Como num jogo especular, refaziam imagens sobre si próprios, se vendo sendo vistos.

4) A cobertura da mídia é essencial. As reportagens em jornais, rádios e televisões suscitavam debates, risos e emoções. Várias vezes os instrutores se sentavam em roda, após as atividades, para ler e discutir uma matéria veiculada. Tudo isso ajudou a criar um novo esquema nós/eles: "nós", os participantes do projeto Juventude e Polícia, e "eles", a sociedade e a mídia vendo um policial em uma cena fora do comum. Isso rapidamente substituiu o primeiro nós/eles: "nós", os policiais; "eles", o AfroReggae. Um grupo de policiais foi treinado e se apresentou no início de 2005 com a banda AfroReggae em um programa de televisão de grande audiência. Em seguida, fez várias apresentações públicas. Esse fato ajudou o projeto a tornar-se mais conhecido não só em Minas Gerais, mas em outros Estados.

5) Em 2005, nas semanas em que policiais (depois de treinados durante quatro semanas dentro dos batalhões) ingressaram em favelas para oferecer aos jovens oficinas de percussão, grafite, basquete e dança, as dinâmicas de estranhamento-surpresa-integração entre os dois grupos foram ainda mais intensas. Uma das técnicas utilizadas foi a dos "jogos da verdade", em que policiais e jovens se sentavam em rodas, depois das atividades, para conversas bastante tensas sobre as experiências dos jovens com a polícia e as experiências dos policiais em rondas dentro das favelas. As perguntas e queixas (o diálogo começava com "tudo aquilo que você sempre quis saber sobre a polícia") invariavelmente começavam com o tema da abordagem policial. A "dura" é uma experiência freqüentemente percebida como humilhante por jovens negros das favelas ${ }^{2}$. De novo, as relações diretas e sem mediações parecem ter sido a fórmula que permitiu o surgimento de uma lógica terapêutica e curativa do tipo "verdade e reconciliação". Nessas dinâmicas, os policiais descobriam que admitir e reconhecer a existência do "bias" racial, de classe e de geografia nas práticas policiais era o primeiro passo para a desobstrução da comunicação. Depois que a "verdade" era reconhecida, a possibilidade da "reconciliação" estava aberta. O resto era operado pela mágica da música e da arte. Como resultado dessa "pedagogia do tambor", novas imagens e relações foram criadas.

Entre os problemas e limitações do projeto estão sua difícil replicabilidade por outros grupos culturais em outros Estados. A carga emocional e simbólica incorporada pelo AfroReggae (nascido no contexto de uma chacina policial) é responsável por boa parte do impacto produzido nas primeiras aproximações com a Polícia. A capacidade de mobilizar permanentemente a mídia e criar a lógica especular essencial ao projeto também é de difícil reprodução em outros Estados, por grupos culturais locais. Um último problema criado pelo sucesso do projeto e por sua forte visibilidade nos meios de comunicação é a resistência de importantes setores policiais. Pesquisadores do Cesec estão avaliando os impactos do projeto por meio de grupos focais, entrevistas e surveys. Evidências iniciais indicam que um contingente não desprezível de comandantes e, mesmo, de praças considera que "não é papel da polícia aparecer tocando tambor na televisão" (os resultados da avaliação serão publicados em 2007). Em outras palavras, trata-se de um projeto polêmico que objetiva precisamente provocar surpresas e transformar imagens tradicionais da polícia. Na medida em que os objetivos se realizam, a oposição a essas mudanças (e aos métodos dessas mudanças) se amplifica. Em 2006, o Comando da Capital da PM de Minas Gerais pretende institucionalizar o Juventude e Polícia como um programa regular.

No plano nacional, obviamente ainda há enormes barreiras a serem superadas. A primeira é persuadir comandantes de polícia a reconhecer 
que as barreiras entre jovens e policiais é algo que afeta o conjunto da sociedade. A segunda é convencê-los de que iniciativas nas quais os jovens, na primeira pessoa, através de música e arte, têm encontros diretos com policiais são poderosos instrumentos de criação de uma polícia mais moderna e democrática.

\section{Considerações finais}

Em contraste com os baixos investimentos governamentais em relação à polícia e à reduzida participação de organizações da sociedade civil em experiências de segurança pública, grupos de jovens de favelas - que tematizam a violência urbana e a violência policial e buscam produzir imagens alternativas aos estereótipos da criminalidade - constituem parte das respostas mais vitais ao problema da violência nos últimos anos. $\mathrm{O}$ grupo AfroReggae, que tem se notabilizado como um típico tradutor nas relações entre os jovens da favela e a cidade formal, vem usando o símbolo de sua história de origem, ligada a uma chacina policial, para desenvolver um trabalho pioneiro de cooperação com a polícia, revertendo expectativas e contrariando profecias (de ódio e vingança em relação à corporação policial). Com o projeto Juventude e Polícia, criou-se uma experiência com uma característica específica, que sublinha o papel insubstituível dos próprios jovens de favelas na construção de novas relações polícia e sociedade.

Implicados na tragédia da violência como principais vítimas e como principais protagonistas, os jovens das periferias terão necessariamente um papel decisivo nas respostas para reduzi-la. Alguns grupos, na condição de novos mediadores, parecem demonstrar, ainda que localizadamente, que é possível oferecer respostas criativas num campo com pequena tradição participativa de entidades civis. Tais novidades não deveriam ser desprezadas pelos que pretendem acompanhar as saídas que a sociedade brasileira vai produzir, nesta década, para enfrentar a violência e construir caminhos para a segurança, a justiça e a cidadania.

\section{Referências}

1. Souza ER, Minayo MCS, Silva CMFP, Reis AC, Malaquias JV, Veiga JPC, et al. Análise temporal da mortalidade por causas externas no Brasil: décadas de 80 e 90. In: Minayo MCS, Souza ER, organizadores. Violência sob o olhar da saúde: a infrapolítica da contemporaneidade brasileira. Rio de Janeiro: Ed. Fiocruz; 2003.

2. Ramos S, Musumeci L. Elemento suspeito: abordagem policial e discriminação na cidade do Rio de Janeiro. Rio de Janeiro: Civilização Brasileira; 2005.

3. Leeds E. Rio de Janeiro. In: Koonings K, Dirk K, editores. Fractured cities: social exclusion, urban violence and contested spaces in Latin America. London: Verso. [No prelo].

4. Soares LE. Meu casaco de general: quinhentos dias no front da segurança pública do Rio de Janeiro. São Paulo: Companhia das Letras; 2000.

5. Minayo MCS, Souza ER, organizadores. Missão investigar: entre o ideal e a realidade de ser policial. Rio de Janeiro: Garamond; 2003.

6. Lemgruber J, Musumeci L, Cano I. Quem vigia os vigias? Rio de Janeiro: Record; 2003.

7. Cano I. Letalidade da ação policial no Rio de Janeiro. Rio de Janeiro: Iser; 1997.

8. Soares LE, Bill MV, Athayde C. Cabeça de porco. Rio de Janeiro: Objetiva; 2005.

9. Sento-Sé JT, organizador. Prevenção da violência: o papel das cidades. Rio de Janeiro: Civilização Brasileira, 2005.
10. Guindani M. A criação de um novo paradigma em Diadema. In: Sento-Sé JT, organizador. Prevenção da violência: o papel das cidades. Rio de Janeiro: Civilização Brasileira; 2005. p. 117-45.

11. Ramos S, Paiva A. Mídia e violência: como os jornais retratam a violência e a segurança pública no Brasil. Boletim Segurança e Cidadania 2005; 9:1-16.

12. Landim L, organizador. Sem fins lucrativos: as organizações não-governamentais no Brasil. Rio de Janeiro: Iser; 1988.

13. Pandolfi D, Grynzspan M, organizadores. A favela fala. Rio de Janeiro: FGV; 2003.

14. Neat P, Platt D. Culture is our weapon: AfroReggae in the favelas of Rio. London: Latin America Bureau; 2006.

15. Bill MV, Athayde C. Falcão: meninos do tráfico. Rio de Janeiro: Objetiva; 2006.

16. Júnior J. Da favela para o mundo: a história do grupo cultural AfroReggae. Rio de Janeiro: Aeroplano; 2003.

17. Yúdice G. A conveniência da cultura: usos da cultura na era global. Belo Horizonte: Ed. UFMG; 2004.

18. Ochoa AM. Entre los deseos y los derechos: un ensaio crítico sobre políticas culturales. Bogotá: Instituto Colombiano de Antropología e Historia; 2003.

Artigo apresentado em 24/03/2006

Aprovado em 4/04/2006

Versão final apresentada em 11/04/2006 